\section{"Tudo é trabalho": representações sociais de gestores de transportes sobre o trabalho intensificado.}

\author{
Ariane Serpeloni Tavares \\ Rosemeire Aparecida Scopinho
}

\section{RESUMO}

O objetivo do artigo é apresentar os resultados e análises oriundos de uma pesquisa qualitativa que buscou compreender as representações sociais (RSs) de gestores de logística sobre o trabalho intensificado. Foram realizadas dez entrevistas semiestruturadas com gestores que atuavam na área de transportes, em empresas privadas de grande porte. Os resultados apontaram que os gestores vivenciavam uma condição laboral intensificada, caracterizada pelo elevado ritmo e pela extensão da jornada, dentro e fora do local de trabalho. Os entrevistados revelaram a existência de consequências paradoxais do trabalho intensificado: por um lado, ele causava problemas na saúde, invadia o espaço privado e trazia dificuldades para a conciliação das diversas esferas da vida; por outro, suportar e aceitar as condições de trabalho intensificadas aumentava as chances de crescimento profissional e diminuía os riscos de perder o emprego. Quanto às causas do trabalho intensificado, os gestores tenderam a atribuir ao sujeito a responsabilidade pela intensificação laboral. Tendo em vista conteúdos de caráter ideológico que formam o pano de fundo para a construção das representações sociais, identificamos que as RSs dos gestores ancoravam-se na ideologia gerencial, que naturaliza as condições de trabalho intensificadas.

Palavras-chave: Intensificação do Trabalho; Gestores; Transportes; Representações Sociais.

\section{ABSTRACT}

\section{"All is work": Social representations of transports managers about intensified work.}

The objective of the article is to present the results and analyzes from a qualitative research that sought to understand the social representations (SRs) of logistics managers about intensified work. Ten semi-structured interviews were conducted with managers who worked in the transport area, in large private companies. The results showed that the managers experienced an intensified work condition, characterized by the high pace and length of the journey, both inside and outside the workplace. The interviewees revealed the paradoxical consequences of intensified work: on the one hand it caused health problems, invaded the private space and led to difficulties in reconciling different spheres of life; on the other hand, supporting and accepting intensified working conditions increased the chances of professional growth and reduced the risk of losing their jobs. As for the causes of the intensified work, the managers tended to attribute to themselves the responsibility for the work intensification. Given the ideological contents that form the background for the construction of social representations, we identified that the manager's SRs are anchored in managerial ideology, which naturalizes intensified working conditions.

Keywords: Work Intensification; Managers; Transports; Social Representation.

\section{Sobre os Autores}

\section{A. S. T.}

http://orcid.org/0000-0001-96046844

Universidade Federal de São

Carlos, São Carlos, SP ariserpeloni82@yahoo.com.br

\section{R. A. S.}

http://orcid.org/0000-0002-27714770

Universidade Federal de São

Carlos, São Carlos, SP scopinho@ufscar.br

\section{Direitos Autorais}

Este é um artigo aberto e pode ser reproduzido livremente, distribuído, transmitido ou modificado, por qualquer pessoa desde que usado sem fins comerciais. $O$ trabalho é disponibilizado sob a licença Creative Commons CC-BY-NC 


\section{2క' INTERACÃO EM PSICOLOGIA}

O presente artigo tem como propósito apresentar os resultados oriundos de uma pesquisa que teve como objetivo geral compreender as representações sociais (RSs) sobre o trabalho intensificado, construídas e partilhadas entre gestores de logística de transportes. As RSs são formas de conhecimento socialmente elaboradas, por meio das quais se constrói uma realidade comum a um conjunto social e têm a função de orientar a forma de interpretar e reagir ao que acontece no mundo (Jodelet, 1989/2001; Jovchelovitch, 2007). Neste sentido, o propósito da pesquisa foi compreender como os gestores interpretavam e reagiam ao trabalho intensificado, que consiste em um modo de trabalhar que demanda um alto esforço físico e/ ou mental do sujeito e decorre de contínuos processos históricos de intensificação laboral (Dal Rosso, 2008).

Todo trabalho envolve gasto de energia e esforço por parte do trabalhador, entretanto, há variação no grau de intensidade do esforço que cada atividade exige. A intensidade consiste no "(...) esforço realizado por uma pessoa ou grupo na execução de um conjunto de tarefas em determinado período de tempo" (Dal Rosso, 2011, p. 231). Deste modo, intensificar o trabalho envolve manipular o seu nível de intensidade com o objetivo de elevar ou meIhorar os resultados auferidos, pois: "(...) quanto maior é a intensidade, mais trabalho é produzido no mesmo período de tempo considerado" (Dal Rosso, 2008, p. 21). Um trabalho intensificado envolve tanto o elevado esforço intensivo, ou seja, alto ritmo de trabalho, quanto o elevado esforço extensivo, isto é, jornadas laborais extensas (Green, 2004). Algumas práticas de gestão que contribuem para a intensificação do trabalho podem ser destacadas: prolongamento das jornadas; aumento do ritmo e da velocidade de execução das atividades; exigência de polivalência; gestão por resultados e adoção de novas tecnologias, como os dispositivos móveis de comunicação e informação (Dal Rosso, 2008).

Sob o ponto de vista de Pina (2012), a intensificação do trabalho refere-se a um processo social e histórico específico ao modo de produção capitalista e consiste em um processo pelo qual se obtém o aumento da intensidade em uma determinada situação concreta e, portanto, não ocorreu da mesma forma em todas as épocas e períodos do desenvolvimento da produção capitalista. Neste sentido, o trabalho intensificado vivenciado na atualidade insere-se no contexto das mudanças econômicas, sociais, políticas e ideológicas que levaram à crise do capitalismo na década de 1970 e que tiveram repercussões para a organização do trabalho, com destaque para a ampliação da gestão flexível e para a introdução de novas tecnologias de informação (Dal Rosso, 2008).
Ariane Serpeloni Tavares e Rosemeire Aparecida Scopinho

No contexto brasileiro, este autor constatou que os trabalhadores perceberam o processo de intensificação do trabalho e apontaram que houve alongamento da jornada, acumulação de tarefas, aumento da exigência de polivalência e flexibilidade, elevação da cobrança de resultados e aumento no ritmo de trabalho. Segundo estudo de Lemos et al., (2016), as empresas têm promovido a intensificação laboral através de novos modos de organização do trabalho e políticas de recursos humanos que envolvem a exigência de polivalência e flexibilidade, gestão por resultados, remuneração variável, extensão da jornada e aumento do ritmo de trabalho, bem como adoção de tecnologias de informação. Quanto às tecnologias, Cavazotte et al., (2014) destacam que o uso de smartphones fornecidos pelas empresas é capaz de promover a extensão da jornada de trabalho além do horário regular e do contexto social onde se dá tradicionalmente, bem como intensificar as demandas laborais.

Se, por um lado, o trabalho intensificado pode trazer ganhos de produtividade para a empresa, ele pode também levar a prejuízos de ordem pessoal, laboral e social para os trabalhadores (Blanch, 2011), como a ocorrência de acidentes de trabalho, lesões, transtornos psíquicos, doenças crônicas, como hipertensão e doenças cardiovasculares e interferência demasiada do trabalho na vida privada, dentre outros problemas (Almeida, 2006; Cavazzote et al., 2014; Dal Rosso, 2008; Lemos et al., 2016; Máximo et al., 2014; Nascimento, 2012; Pina, 2012). Diante disto, podemos entender o trabalho intensificado como um campo de disputa entre interesses dos trabalhadores e dos empregadores. Neste sentido, as RSs que os trabalhadores constroem sobre o tema podem auxiliar na compreensão deste fenômeno, já que evidenciam a forma como os sujeitos submetidos ao trabalho intensificado interpretam e lidam com ele.

As RSs são entendidas como formas de conhecimento socialmente elaboradas e partilhadas, por meio das quais se constrói uma realidade comum a um conjunto social. Nas palavras de Jovchelovitch (2007, p. 81$)$ : "[a]s representações sociais são uma estratégia desenvolvida por atores sociais para enfrentar a diversidade e a mobilidade de um mundo que, embora pertença a todos, transcende a cada um individualmente". As RSs, portanto, são saberes, conhecimentos práticos, que guiam a forma de interpretar e reagir ao que acontece no mundo. Elas são produzidas através da interação nos mais diversos locais em que, por meio da comunicação, as pessoas analisam os acontecimentos e formulam filosofias espontâneas e não oficiais, que guiam seu modo de comportar-se (Moscovici, 2000/2007). Neste sentido, o local de trabalho 


\section{HZ INTERACÃOEM
PSICOLOGIA}

pode proporcionar que tais relações de mediação ocorram. Ademais, tendo em vista que as empresas adotam diversas práticas de comunicação, como treinamentos, reuniões, veiculação de informações impressas e eletrônicas, etc., embebidas em discursos ideológicos1, entendemos que este é um espaço relevante para a produção das RSs. A empresa, deste modo, enquanto arena pública e sistema social, é um espaço importante para a construção de representações, embora, caiba destacar que os sujeitos não são passivos neste processo: eles estão, diretamente, implicados na produção, transformação e comunicação das RSs.

Este caráter ativo do sujeito destaca ainda mais o papel dos gestores na produção e disseminação de RSs, pois estes trabalhadores estão em uma posição paradoxal diante da intensificação do trabalho, já que, concomitantemente ao papel de representantes da empresa, eles também estão sujeitos às consequências da organização do trabalho. Suas representações sociais, portanto, podem envolver de forma especial, a ideologia gerencial presente nas práticas e discursos organizacionais, o que traz elementos ainda mais interessantes para a compreensão do tema. A ideologia gerencial, segundo Gaulejac (2005/2007) associa-se aos valores "positivos" como o gosto do empreender, o desejo de progredir, a celebração do mérito e o culto da qualidade, o que vai ao encontro das aspirações humanas e leva os trabalhadores a incorporarem a necessidade de serem rentáveis. As ideologias fazem parte do que Jodelet (2009) denomina de esfera transubjetiva do contexto de produção das RS, que consiste em tudo o que perpassa os sujeitos. Assim, buscamos neste artigo, compreender como os elementos desta esfera, em especial a ideologia gerencial, pode servir de ancoragem para as RSs sobre trabalho intensificado dos gestores.

Para expor os resultados da pesquisa realizada, organizamos o texto em cinco seções, além desta introdução. Em um primeiro momento, apresentamos o método adotado, seguido pela caracterização do trabalho intensificado vivenciado pelos gestores. Na sequência, apresentamos os paradoxos do trabalho intensificado e, a seguir, analisamos as explicações que os gestores deram para a existência do trabalho intensificado, apontando elementos do contexto ideológico que podem servir como pano de fundo para a construção destas representações sociais. Nas considerações finais, levantamos as principais contribuições, limitações e sugestões para a continuidade do estudo da temática.

\section{MÉTODO}

Participaram da pesquisa dez trabalhadores que ocupavam cargos de liderança intermediária (coordenadores e gerentes) em empresas privadas de grande porte do ramo de logística, ou que atuavam na área de transportes de empresas de outros segmentos, das regiões sul e sudeste do Brasil. 0 campo empírico foi escolhido tendo em vista que o setor de transporte rodoviário, além de ser um dos mais importantes para a dinâmica econômica da sociedade contemporânea centrada nas atividades de comércio e prestação de serviços, segundo Dal Rosso (2008), figura entre os mais intensificados no contexto brasileiro. Ademais, ainda de acordo com o autor, as empresas de grande porte são as que conseguem mais facilmente introduzir processos que intensificam o trabaIho, pois têm condições de adotar novas tecnologias de gestão do trabalho que produzem resultados por meio de maior exigência de desempenho dos trabalhadores. Não foram localizados, na literatura ${ }^{3}$, estudos sobre o trabaIho intensificado que abordassem o trabalho gerencial no ramo de transportes. Os trabalhadores entrevistados eram responsáveis por gerir, de forma eficaz, operações de armazenagem, carregamento, transporte e entrega de mercadorias e insumos.

Para participar da pesquisa, era necessário que os gestores tivessem vivenciado o trabalho intensificado2, ou seja, ter trabalhado sob condições como as apontadas por Burke e Fiksenbaum (2008): a) prazos curtos; b) escopos imprevisíveis; $\mathrm{c}$ ) responsabilidades relacionadas a mais de uma função; d) atender eventos de trabalho fora do horário regular; e) disponibilidade 24 horas por dia; f) responsabilidade por resultados; g) viagens em grande volume; $h$ ) jornadas superiores a dez horas por dia, dentre outras. Não era necessário, entretanto, que todos estes requisitos estivessem presentes em conjunto, mas que a vivência subjetiva do trabalho apontasse, especialmente, o elevado ritmo e as longas jornadas.

Foram realizadas entrevistas semiestruturadas (Minayo, 2009), nas quais se utilizou um roteiro com os temas a serem explorados, sem restringir, entretanto, a livre expressão do entrevistado. 0 roteiro contemplava: dados pessoais; rotina de trabalho; responsabilidades; trajetória profissional; aspectos organizacionais; e reflexões sobre o trabalho intensificado, como sua definição, suas causas e suas consequências. Segundo Jodelet (1989/2001), o discurso está entre as mais importantes formas de apre- 


\section{HZ INTERACÃOEM
PSICOLOGIA}

ensão das RSs e, deste modo, a entrevista representa um valioso recurso metodológico para a compreensão da estrutura do pensamento.

O conteúdo das entrevistas foi gravado, mediante consentimento dos entrevistados, e transcrito. A duração média das entrevistas foi de uma hora e 15 minu The objective of the article is to present the results and analyzes from a qualitative research that sought to understand the social representations (SRs) of logistics managers about intensified work. Ten semi-structured interviews were conducted with managers who worked in the transport area, in large private companies. The results showed that the managers experienced an intensified work condition, characterized by the high pace and length of the journey, both inside and outside the workplace. The interviewees revealed the paradoxical consequences of intensified work: on the one hand it caused health problems, invaded the private space and led to difficulties in reconciling different spheres of life; on the other hand, supporting and accepting intensified working conditions increased the chances of professional growth and reduced the risk of losing their jobs. As for the causes of the intensified work, the managers tended to attribute to themselves the responsibility for the work intensification. Given the ideological contents that form the background for the construction of social representations, we identified that the manager's SRs are anchored in managerial ideology, which naturalizes intensified working conditions.

Keywords - Work Intensification; Managers; Transports; Social Representation. tos e foram realizadas, em sua maioria, fora do ambiente e horário de trabalho dos gestores, por meio de chamadas de vídeo do Skype, recurso este fundamental para a condução da pesquisa por facilitar o acesso aos entrevistados em várias localidades, reduzir os custos de pesquisa, permitir maior flexibilidade no agendamento de horários e amenizar problemas decorrentes das remarcações e cancelamentos que, muitas vezes, ocorreram próximo do horário agendado. 0 contato foi feito diretamente com os gestores entrevistados, por meio do método de bola de neve (Vinuto, 2014) e não houve, deste modo, intermediação das empresas em que trabalhavam.

A quantidade de sujeitos entrevistados foi determinada pelo critério de saturação, ou seja, o número de participantes foi definido a partir das necessidades do processo de conhecimento do tema em questão (Deslandes, 2009). Os dez entrevistados - sete gerentes e três coordenadores - eram do sexo masculino, tinham entre 27 e 46 anos de idade e entre cinco e 23 anos de experiência na área de transportes. Apenas um dos coordenadores estava cursando o ensino superior na época das entrevistas e os demais eram graduados ou pós-graduados. A maioria era casada e tinha filhos. Trabalhavam em empresas privadas de grande porte, predominantemente sociedades anônimas de capital fechado.

A Análise de Conteúdo Temática foi utilizada para identificar os núcleos de sentido que compunham a comunicação, e seguiu a proposta de Gomes (2009), que contempla a leitura compreensiva e exaustiva do conteúdo, a exploração do material (análise propriamente dita) e a elaboração da síntese interpretativa.

A pesquisa foi aprovada pelo Comitê de Ética em Pesquisas com Seres Humanos, inclusive quanto à inexigibilidade de autorização das empresas que empregavam os entrevistados e atendeu rigorosamente à Resolução $n^{\circ} 466 / 2012$ do Conselho Nacional de Ética em Pesquisa (Brasil, 2012). Os nomes atribuídos aos entrevistados são fictícios.

\section{CARACTERIZAÇÃO DO TRABALHO GERENCIAL INTENSIFICADO NA ÁREA DE TRANSPORTES}

De maneira geral, as posições de gestão incluem atividades de planejamento, organização e acompanhamento do trabalho executado pelos subordinados, para que sejam atingidos os objetivos definidos pela empresa. No caso estudado, os gestores relataram ter responsabilidades amplas e variadas, que envolviam tudo que estivesse relacionado ao bom funcionamento das operações logísticas, como: gestão de pessoas; gestão de ativos operacionais; gestão financeira; gestão dos processos operacionais; saúde e segurança; relacionamento com clientes, dentre outras. Esta complexidade da função gerencial pode ser considerada como um dos elementos que contribuem para a elevada intensidade do trabalho desta categoria, já que a gestão de áreas diversificadas exige polivalência por parte dos gestores, o que, segundo Dal Rosso (2008), é um fator de intensificação laboral.

As representações sociais dos entrevistados sobre o que seria um trabalho intensificado giraram em torno de quatro conceitos principais: a) tempo escasso; b) diversificação de atividades; c) ocorrência de imprevistos e; d) vivência do trabalho 24 horas por dia. As definições dos entrevistados incluíram, deste modo, tanto o esforço extensivo quanto o esforço intensivo, pois o elevado ritmo de trabalho e o prolongamento da jornada dentro e fora da empresa foram mencionados pelos entrevistados como elementos que caracterizavam o trabalho intensi- 
ficado.

Quanto ao elevado ritmo de trabalho - os entrevistados o expressaram por meio de frases como: "(é) um trabalho muito dinâmico.", "eu me sinto, nossa, acelerado é pouco!" e "a gente está em um ambiente nervoso". Eles também caracterizaram o dia de trabalho como "corrido", "agitado", "puxado" e "pesado", dentre outras expressões que demonstram que o ritmo de trabalho necessário para a realização das atividades era elevado.

Referente à duração do trabalho, os entrevistados, em geral, relataram realizar longas jornadas, que ultrapassavam 10 horas diárias, sendo que a maioria possuía jornadas de 12 horas por dia, aproximadamente. Ademais, eles expuseram a existência de demandas laborais nos fins de semana e à noite, além da necessidade de estarem disponíveis 24 horas por dia por meio de dispositivos de comunicação.

A onipresença do telefone corporativo, um elemento fundamental para a intensificação do trabalho dos gestores entrevistados, foi expressa em frases como: "o telefone não desliga", "está sempre comigo", e "ando sempre grudado (...) não deixo solto". 0 uso das tecnologias de comunicação mostrou-se um elemento primordial na intensificação do trabalho dos gestores, especialmente diante de um trabalho de caráter imaterial (Grisci, 2011) que, segundo Mansano (2009) pode, mais facilmente, ser realizado em qualquer tempo e espaço.

Consideramos, assim, que a polivalência que a atividade de gestão exige, a sua imaterialidade e o uso de tecnologias têm importante papel na intensificação laboral dos gestores e remetem às características da terceira onda de intensificação do trabalho apontada por Dal Rosso (2008).

\section{PARADOXOS DO TRABALHO INTENSIFICADO}

Uma representação social identificada e relevante de destacar refere-se à concepção, por parte dos gestores entrevistados, de que o trabalho intensificado trazia consequências nocivas à esfera privada, mas, por outro lado, permitia compensações na esfera profissional. As principais consequências negativas apontadas pelos gestores foram: a) dificuldades de conciliação da vida privada com as demandas laborais; b) diluição das barreiras entre tempo de trabalho e não trabalho e; c) impactos na saúde. Os entrevistados estabeleceram uma relação clara entre as demandas do trabalho e as dificuldades que elas causavam em outras esferas da vida: família, lazer, descanso, cuidados com a saúde e estudos. Por outro lado, estas dificuldades foram apresentadas, muitas vezes, como algo natural e inerente à função gerencial, cabendo a eles saber equilibrar as demandas de todas as esferas da vida. Os gestores entrevistados também consideravam que o trabalho que executavam invadia o tempo de não trabalho, tanto em decorrência da permanência das preocupações com o trabalho (metas, pendências, soluções de problemas), como pelo uso dos smartphones corporativos, que não podiam ser desligados e os colocavam sob alerta permanente. Com relação aos impactos na saúde, foram apontados problemas gástricos, musculares, cardiovasculares, obesidade e variações de peso, problemas capilares, estresse, ansiedade, dificuldades de concentração e desgaste físico e mental. Estes problemas, analisados sob a perspectiva da Medicina Social Latino Americana (Laurell \& Noriega, 1989), estavam relacionados, principalmente, à sobrecarga psíquica presente nas condições laborais dos gestores, que era, ainda, potencializada pela extensão do trabalho para outros tempos e espaços.

Quanto às vantagens do trabalho intensificado apontadas pelos entrevistados, destacam-se os benefícios financeiros e de carreira decorrentes da aceitação destas condições laborais. Na percepção deles, não eram todas as pessoas que suportavam ou possuíam o perfil adequado para trabalhar sob condições intensificadas e, portanto, aqueles que as aceitavam recebiam melhores remunerações e bonificações, bem como eram reconhecidos, promovidos e conseguiam crescer profissionalmente. Temos que ressaltar, entretanto, que, na opinião dos entrevistados, não havia opções de progredir profissionalmente na área de logística sem que isto provocasse um aumento na intensidade do trabalho. Por isso, recusar a intensificação, poderia implicar em não progredir na carreira, perder o emprego ou ter que mudar de ramo.

Outro aspecto interessante apontado pela pesquisa foi a preferência dos gestores por trabalhos que envolviam alto ritmo, expressa em frases como: "eu prefiro trabalhar num trabalho intenso do que em um trabalho que seja morno"; e "se o dia está calmaria (...) se ele está tranquilo demais, é um dia péssimo para mim, porque eu sei que eu não vou produzir nada e isso me deixa ansioso".

Para a compreensão desta questão, bem como da percepção que os gestores tinham sobre a existência de vantagens e recompensas do trabalho intensificado, consideramos importante considerar o papel das ideologias na constituição das RSs. Para Jodelet (2009) as ideologias pertencem à esfera transubjetiva das RSs e perpassam todo o conjunto social, influenciando na construção e difusão das RSs. No caso estudado, ideologias como a do 
gerencialismo (Gaulejac, 2005/2007), presentes no contexto social dos gestores, parecem fornecer conteúdos relevantes a ser incorporados nas representações sociais do grupo analisado. 0 gerencialismo estimula os trabaIhadores a, constantemente, dar provas do seu valor e da sua contribuição para a empresa no sentido de construir "um tempo integralmente rentável" (Gaulejac, 2005/2007, p. 101). Além disso, valoriza o mérito, ou seja, o esforço individual como requisito para o sucesso. A incorporação desta forma de pensar à prática profissional dos gestores leva-os a valorizar a produtividade, a rentabilidade e a disponibilidade integral à empresa e, em decorrência, pode fazer com que as condições de trabalho, que deveriam ser questionadas, passem a ser suportadas, aceitas e, até mesmo, percebidas como satisfatórias. Neste sentido, podemos entender que a ideologia gerencialista é um importante elemento na construção das RSs sobre o trabalho, guiando a forma como os sujeitos interpretam o que ocorre no ambiente organizacional.

\section{AS EXPLICAÇÕES SOBRE O TRABALHO INTENSIFICADO}

As RSs são explicações que os sujeitos constroem sobre sua realidade e são criadas para que eles possam estar informados sobre o que acontece em seu mundo, saber dominá-lo, interpretá-lo e ajustar-se a ele (Jodelet, 1989/2001; Moscovici, 2000/2007). Assim, um dos conteúdos cruciais das representações sociais dos entrevistados para o entendimento da questão abordada na pesquisa são as atribuições das causas do trabalho intensificado. A construção das explicações fundamenta-se nas afiliações das pessoas e dos grupos, ou seja, cada grupo social encontra motivos diferentes para explicar o que acontece no mundo, dependendo de suas vivências, de suas raízes ideológicas, de sua posição social, do contato que tiveram com os conhecimentos do universo reificado, etc. (Jodelet, 1989/2001; 2009; Moscovici, $2000 / 2007)$. Tendo isto em vista, buscamos captar as explicações que os entrevistados tinham acerca da realidade concreta que vivenciavam. Apesar de trabalharem em empresas distintas, com diferenças nos modos de organização e nas condições de trabalho, havia um contexto social comum aos entrevistados e que afetava as suas representações sociais.

Em relação ao motivo de vivenciarem um trabalho intensificado, os gestores relataram que isto se devia, em síntese, aos fatores: pessoais, profissionais e aqueles re- lacionados à empresa, ao ramo de atuação e ao tipo de operação realizada, como veremos em alguns depoimentos que exemplificam estes pontos de vista.

Quando questionados sobre quem seriam os responsáveis pelo trabalho intensificado, grande parte dos entrevistados afırmou que eram os próprios gestores, opinião que foi expressa em trechos como:

Nós mesmos (somos responsáveis pela intensidade do trabalho). Nós não somos organizados. Nós, às vezes, não damos, de fato, um direcionamento claro. Isso faz com que você fique sobrecarregado (José, Gerente Geral).

(Estar disponível 24 horas é) uma opção (...). Ninguém vai apontar a arma para a minha cabeça e dizer 'cara, você tem que atender o telefone' (Maurício, Gerente de Operações).

Os processos dependem do gerente. Então, eu acho que os principais fatores estão vinculados ao gestor. Então, 70\% do teu tempo, eu acho, tu consegue amenizar ele por conta da forma como tu vai gerir os teus pares, os teus clientes, a tua matriz (Fábio, Gerente de Operações).

Os entrevistados, ainda, atribuíram a ocorrência do trabalho intensificado a características pessoais, como ansiedade, desorganização, incapacidade de gerir o tempo, falta de disciplina, "jeito de ser" ou "modo de trabalhar". A maior parte dos entrevistados também ressaltou a importância de fatores como maturidade, experiência e fase da carreira, ou seja, aspectos profissionais, como elementos relevantes para a definição do nível de intensidade do próprio trabalho. Para os entrevistados, a experiência profissional conquistada com o tempo permitia maior domínio sobre a equipe e sobre o trabalho, o que levava à redução dos erros e do tempo necessário para a execução das atividades. A redução da intensidade também estava relacionada à maior maturidade, autoconfiança e capacidade de se negar a realizar tarefas não condizentes com suas responsabilidades, como pode ser exemplificado no trecho a seguir:

Com a idade os valores vão mudando, e tu começa a aprender alguns atalhos também, começa a entender o que é realmente importante e o que é apenas uma vaidade do teu chefe, o que é uma vaidade do teu 


\section{INTERACÃO EM PSICOLOGIA}

cliente (...). E conforme tu vai construindo a tua vida, tu vai conquistando mais confiança para dizer mais nãos (...). (Fábio, Gerente de Operações).

Os gestores também apontaram que a consolidação da carreira permitia que eles tivessem melhores condições de fazer escolhas em relação à vida profissional e às condições de trabalho: "Eu já tenho poder de escolha, já tenho uma carreira sólida, construída, que eu posso optar por algumas coisas" (Henrique, Gerente de Operações).

Constatamos que os gestores reconheciam ter influência sobre a intensidade do trabalho dos seus subordinados pelo fato de serem líderes. Os entrevistados abordaram tanto a influência dos seus superiores em relação ao seu nível de intensidade quanto a sua própria autonomia para definir a intensidade do trabalho dos seus subordinados, demonstrada em frases como: "a tropa é o espelho do comandante", "tu é que dá o ritmo" e "(você) tem vergonha de trabalhar menos do que teu próprio chefe, não é?". A autonomia em relação à redução da intensidade do trabalho dos subordinados, entretanto, foi apontada como restrita diante da necessidade de trabalhar com quadros enxutos e orçamento restrito.

Outro ponto considerado pelos entrevistados como um fator que interferia no nível de intensidade do trabaIho refere-se ao ramo de atuação. Não estamos dizendo que a logística de transportes é o ramo mais intensificado dentre todos, mas que era considerado pelos entrevistados como um dos mais intensificados. Dal Rosso (2008) também apontou que o setor de transportes estava entre os mais intensificados dentre os setores envolvidos em sua pesquisa. Foi unânime, na concepção dos entrevistados, que o trabalho nas áreas operacionais de empresas de logística ou no setor de logística de transportes de uma empresa de qualquer ramo era mais intensificado do que em outras, por fatores relacionados às características da área de logística de transportes, tais como a imprevisibilidade, o dinamismo, a cultura de urgência, a dispersão geográfica e a ininterrupção das operações, que podem ser sintetizadas no trecho a seguir:

(...) o transporte ele é bem imprevisível, dinâmico, vamos dizer, então, é uma indústria a céu aberto. Os caminhoneiros estão todos rodando (...). São 180 linhas de produção acontecendo ao mesmo tempo (Maurício, Gerente de Operações).

Os entrevistados ressaltaram que a intensidade do trabalho era maior nas áreas operacionais, ou seja, naquelas que lidavam diretamente com o transporte, bem como nas operações ininterruptas, já que estas demandavam uma disponibilidade permanente para atender a imprevistos, o que é um fator de intensificação do trabalho, de acordo com Burke e Fiksenbaum (2008). Destaca-se, o papel das tecnologias de comunicação como facilitadores desta disponibilidade permanente para o trabalho, conforme exemplificado nos trechos a seguir:

Quando você fala aí de trabalho mesmo, é 24 horas, porque o telefone não desliga, você sempre fica com o telefone do lado da cama, dois, três, geralmente você nunca tem um telefone só. Às vezes, tem até três (Marcos, Gerente de Transportes).

Telefone, nem se fala, está sempre comigo (...), então eu não deixo de atender nenhuma ligação, mesmo final de semana, madrugada quando precisa, e tem acesso a e-mail também no meu telefone, então também acompanha nos finais de semana que é necessário para não deixar a operação parada (Maurício, Gerente de Operações).

Os entrevistados também consideravam que um fator extremamente relevante para a intensificação laboral era o trabalho como operador logístico, ou seja, a atuação como terceirizado na gestão de logística para uma ou mais empresas clientes levava a um nível de pressão e intensidade muito maior.

Outro aspecto considerado como fator de influência na intensidade do trabalho, na concepção dos entrevistados, foi a qualidade da equipe subordinada ao gestor, já que equipes inexperientes ou com baixa qualificação intensificava o trabalho do gestor pela necessidade de treinar, acompanhar e, em alguns momentos, fazer o trabalho operacional sob responsabilidade da equipe. As reestruturações e os enxugamentos de equipe também foram elencados como motivos de intensificação do trabalho.

Os gestores, ainda, apontaram a cultura da meritocracia como elemento relevante para elevar a intensidade do trabalho. Apesar de considerarem que a meritocracia elevava a intensidade do trabalho, eles concordavam em grande parte com suas premissas e sentiam-se bem trabalhando em empresas que a adotavam, como pode ser verificado nos trechos abaixo:

Cultura de empresa que faz com que todos trabalhem muito é a cultura do pagamento de variável por resultado (Lucas, Gerente de Operações). 


\section{H'INTERACÃO EM PSICOLOGIA}

(...) eu acho que ela (cultura meritocrática) tem uma vantagem (...) é algo que te insere dentro da estratégia da empresa e mostra o que a empresa espera de você. Então, ela te mede de uma forma mais justa, vamos dizer assim (Henrique, Gerente de Operações).

Importante destacar a adesão dos entrevistados à cultura meritocrática e à busca de resultados, que passaram a fazer parte das representações sociais deles sobre a forma de organizar o trabalho. Entendemos que a meritocracia, ou seja, a concepção de que o esforço individual é a chave do sucesso, possui caráter ideológico e influencia na construção das representações sociais. Ter mérito, segundo Faria e Ramos (2015) significa atender às necessidades da empresa e constitui-se, assim, em um sistema de poder e de controle sobre os trabalhadores. A meritocracia estimula a competição individual, responsabiliza os trabalhadores pelo próprio desempenho profissional e pelos resultados organizacionais, independentemente das condições que lhes são dadas para isso. Assim, embora reconhecessem que as metas faziam trabalhar mais, não sofriam por conta delas e replicavam com seus subordinados as exigências de resultados que recebiam de seus superiores.

No tocante ao papel da empresa, os gestores destacaram que a falta de recursos e tecnologias, as reduções de quadro, a baixa qualidade dos processos de apoio às operações, a inexistência de outros profissionais com poder de decisão 24 horas por dia, dentre outros aspectos, tornavam o trabalho mais intenso. Estes aspectos, cabe destacar, são elementos que precarizam o trabalho dos gestores. Apesar de haver reconhecimento por parte dos entrevistados, de um modo geral, em relação ao papel da empresa, nenhum deles considerava que havia uma intencionalidade desta, isto é, eles não reconheciam que a intensificação do trabalho poderia ser uma estratégia da empresa para obter maior lucratividade.

Uma questão muito importante verificada na pesquisa é que, apesar de ter sido possível levantar todos estes fatores ao longo das entrevistas, os gestores apresentaram a tendência de explicar o trabalho intensificado como decorrente de características pessoais. Com isto queremos dizer que, ao ser questionado diretamente sobre o motivo de trabalhar intensamente, a resposta focou em questões pessoais. Parte desta autorresponsabilização pode ser decorrente da baixa prescrição da função gerencial, que confere, por um lado, uma sensação de autonomia, e por outro, um sentimento de maior responsabilidade pela organização do próprio trabalho. Por outro lado, podemos entender que a não responsabilização da empresa ou do
Ariane Serpeloni Tavares e Rosemeire Aparecida Scopinho

modo de produção capitalista está relacionada ao posicionamento ideológico dos gestores. Considerando que as RSs são constituídas, entre outros, de elementos ideológicos (Jodelet, 1989/2001), tais como a responsabilidade do trabalhador pela sua qualificação, pelos seus resultados e pela sua carreira, que são elementos da ideologia gerencialista (Gaulejac, 2005/2007), que naturalizam a intensificação e fornecem conteúdos incorporados e adaptados às representações sociais do grupo de gestores aqui analisadas, ou seja, as representações ancoram-se nos conteúdos ideológicos do gerencialismo. Este quadro ideológico ancora a representação social de que o sujeito é responsável pela intensidade do próprio trabalho. Cabe lembrar que não se pode considerar o trabalho intensificado como uma escolha de quem labora sob estas condições, pois segundo Dal Rosso (2008), a intensificação laboral consiste em uma condição do trabalho contemporâneo, independendo dos desejos, vontades e características de cada trabalhador.

\section{CONSIDERAÇÕES FINAIS}

Por meio da pesquisa, buscamos demonstrar que os gestores de transportes vivenciavam uma condição laboral intensificada, pois suas rotinas de trabalho eram caracterizadas pelo elevado ritmo, bem como pela extensão da jornada, dentro e fora do local de trabalho. A disponibilidade permanente, decorrente da ininterrupção das operações e possibilitada pelo uso de dispositivos móveis de comunicação, também é um elementos que caracteriza a elevada intensidade laboral deste grupo.

Os entrevistados revelaram a existência de representações sociais sobre o trabalho intensificado e suas consequências paradoxais: por um lado ele causava problemas na saúde, invadia o espaço privado e levava a dificuldades na conciliação das diversas esferas da vida; por outro, suportar e aceitar as condições de trabalho intensificadas aumentava as chances de crescimento profissional e diminuía os riscos de perder o emprego.

Quanto às representações sociais relacionadas às causas do trabalho intensificado, pudemos identificar que, em um primeiro momento, os gestores tenderam a atribuir ao sujeito a responsabilidade pela intensificação laboral, elencando características e dificuldades dos próprios gestores como elementos importantes para entender porque o trabalho era tão intenso. Entretanto, ao longo das entrevistas, pudemos constatar que eles identificavam outros fatores para a intensidade laboral, mesmo que de forma indireta. Entre estes fatores, o que mais se 


\section{HT INTERACÃO EM
PSICOLOGIA}

destacou foi a representação social, unânime entre os gestores, de que o setor de transportes e suas peculiaridades - operações ininterruptas, dispersão geográfica, dinamicidade, etc. - estavam na base da intensificação laboral vivenciada. As precárias e intensas condições de trabalho no setor de transportes eram naturalizadas, o que levava os gestores a acreditar que não era possível modificar esta situação e que a aceitação destas condições era fundamental para manter-se e crescer profissionalmente na área. Acreditamos que esta representação social, presente na fala de todos, foi usada constantemente como justificativa para o trabalho intensificado, o que pode ser um grande limitador das tentativas de mudança das condições de trabalho.

Ainda, cabe destacar que pouca responsabilidade foi atribuída à empresa e não houve reconhecimento explícito de que intensificar o trabalho fosse uma estratégia da empresa para obter melhores resultados financeiros. Entendemos que o fato de ocuparem uma posição de liderança nas empresas contribui para reafirmar cotidianamente este modo de interpretar o trabalho intensificado, pois as RSs são produzidas por sujeitos inseridos em um contexto social, ou seja, está imbricado na formação das RSs o funcionamento do sistema social, dos grupos e das interações sociais, além das funções que cada sujeito ocupa na dinâmica social (Jodelet, 1989/2001). Como os sujeitos aderem, embora de forma não passiva, às formas de pensamento da classe ou do grupo ao qual pertencem (Jodelet, 1989/2001), podemos compreender que a interação dos gestores entre si, bem como suas vivências, treinamentos, aprendizados e discursos oriundos do contexto organizacional passam a influenciar no conteúdo das suas representações sociais. Sendo a empresa um campo social impregnado pela ideologia gerencialista, é natural que ela componha as representações destes sujeitos, que as incorporam no seu modo de agir.

Salientamos que as representações não são somente formadas pelo social, mas também formam o social (Jovchelovitch, 2007), de modo que as representações dos gestores sobre o mundo do trabalho também fornecem elementos para a construção das representações de outros grupos sociais, como seus subordinados, familiares, amigos, etc. Isto foi relevante na presente pesquisa, pois a posição ocupada pelos gestores fazia com que, mesmo sofrendo na pele as consequências das condições de trabalho intensificadas, eles as vissem como naturais, inevitáveis e necessárias no mundo contemporâneo, especialmente no ramo de transportes. Assim, as condições laborais que vivenciavam, eram replicadas para seus subordinados e, certamente, os discursos utilizados, impregnados pela ideologia gerencial, afetavam (embora não determinassem) a forma como seus subordinados interpretavam e vivenciavam as suas condições laborais. Deste modo, ao mesmo tempo em que os gestores eram vítimas da intensificação laboral, eles também colaboravam para a manutenção destas condições, pois precisavam contar com a adesão de seus subordinados a este modo de trabalhar, já que os resultados obtidos pelos gestores dependiam do trabalho das suas equipes.

As características da intensificação laboral dos gestores relacionam-se com a polivalência exigida pela função, a imaterialidade do trabalho gerencial, a onipresença das tecnologias de comunicação e a influência do gerencialismo. Estes elementos nos levam a compreender que a intensidade do trabalho verificada no contexto laboral estudado está relacionada à terceira onda de intensificação do trabalho, que, de acordo com Dal Rosso (2008) decorre do emprego de novas tecnologias e modernas formas de gestão do trabalho, com destaque para a exigência de polivalência e a gestão por resultados.

Novas pesquisas sobre este tema poderiam ser enriquecidas através de recortes geracionais, de gênero e até mesmo de origem social acerca das representações sociais do trabalho intensificado. Também podem ser feitos estudos comparativos entre representações sociais de trabalhadores de diferentes setores econômicos, países ou regiões geográficas.

Consideramos que a abordagem do trabalho intensificado no setor de logística de transportes foi bastante frutífera, pois encontramos condições de trabalho intensificadas e também precarizadas, especialmente a não separação entre tempos de trabalho e de não trabalho, decorrente, principalmente, da ininterrupção das operações e do uso das tecnologias de comunicação. Os resultados alcançados, entretanto, podem ser generalizados para os mais diversos setores, visto que o trabalho intensificado não é exclusividade do setor de transportes e mostra-se cada vez mais presente nos diversos ramos, inclusive no setor público.

\section{REFERÊNCIAS}

Almeida, L. L. (2006). Manda quem pode, obedece quem tem juízo: prazer e sofrimento psíquico em cargos de gerência. [Dissertação de Mestrado, Universidade Federal do Rio Grande do Sul] Biblioteca Digital Brasileira de Teses e Dissertações. http://bdtd.ibict.br/vufind/Record/URGS_c05207bbf33f85d82ee4ec368ee58d9b. 


\section{4: INTERACÃO EM PSICOLOGIA}

Blanch, J. M. (2011). Condiciones de trabajo y riesgos psicosociales bajo la nueva gestión. Focad, 14.

Brasil, República Federativa do Brasil. (2012). Resolução $n^{\circ} 466$ de 12 de dezembro de 2012. Dispõem diretrizes e normas regulamentadoras de pesquisas envolvendo seres humanos. http://bvsms.saude.gov.br/bvs/saudelegis/cns/2013/res0466_12_12_2012.html.

Burke, R. J. \& Fiksenbaun, L. (2008). Work hours, work intensity, and work addiction: costs and benefits. In: R.J. Burke \& C. L. Cooper (Eds.), The long work hours culture: causes, consequences and choices (pp. 3-36), Emerald.

Cavazotte, F. S. N., Lemos, A. H. C., \& Brollo, M. S. (2014). Trabalhando melhor ou trabalhando mais?: um estudo sobre usuários de smartphones corporativos. O\&S, 21(68), 769-788. https://doi.org/10.1590/s198492302014000100002.

Dal Rosso, S. (2008). Mais trabalho!: a intensificação do labor na sociedade contemporânea. Boitempo.

Dal Rosso, S. (2011). Intensidade do trabalho. In A. D.Cattani \& L. Holzmann (Orgs.). Dicionário de trabalho e tecnologia. (2a ed., pp. 231-235), Zouk.

Deslandes, S. F. (2009). O projeto de pesquisa como exercício científico e artesanato intelectual. In M. C. S. Minayo (Org.). Pesquisa Social: teoria, método e criatividade (28a ed., pp. 31-60), Vozes.

Faria, J. H. \& Ramos, C. L. (2015). A meritocracia nas organizações contemporâneas: gestão de competência e de desempenho. In Padilha, V. (Org.). Antimanual de gestão: desconstruindo os discursos do management (pp. 23-58), Ideias \& Letras.

Gaulejac, V. (2007). Gestão como doença social: ideologia, poder gerencialista e fragmentação social. (3. Ed), Ideias \& Letras.(Trabalho original publicado em 2005).

Gomes, R. (2009). Análise e interpretação de dados de pesquisa qualitativa. In: M. C. S. Minayo (Org.). Pesquisa social: teoria, método e criatividade. (28a ed., pp. 79-108), Vozes.

Green, F. (2004). Why has work effort become more intense? Industrial Relations, 43(4), 709-741.https://doi. org/10.1111/j.0019-8676.2004.00359.x.

Grisci, C. L. I. (2011). Trabalho imaterial. In A. D.Cattani \& L. Holzmann (Orgs.). Dicionário de trabalho e tecnologia. (2a ed., pp. 456-458), Zouk.

Jodelet, D. (2001). Representações sociais: um domínio em expansão. In Jodelet, D. (Org.). As representações sociais, EdUERJ. (Trabalho original publicado em 1989).
Jodelet, D. (2009). O movimento do retorno ao sujeito e a abordagem das representações sociais. Sociedade e Estado, 24(3), p. 679-712. https://doi.org/10.1590/ s0102-69922009000300004.

Jovchelovitch, S. (2007). Vivendo a vida com os outros: intersubjetividade, espaço público e representações sociais. In Guareschi, P. A.; Jovchelovitch, S. (Orgs.). Textos em representações sociais. (9a ed., pp. 63-85), Vozes.

Laurell, A. C. \& Noriega, M. (1989). Processo de produção e saúde: trabalho e desgaste operário, Hucitec.

Lemos, A. H. C., Gottlieb, L. S. N., \& Costa, A. S. M. (2016). Pressure, performance and prestige: dilemmas for contemporary professionals. O\&S, 23(79), 539-552. https://doi.org/10.1590/1984-9230791.

Mansano, S. R. V. (2009). Transformações da subjetividade no exercício do trabalho imaterial. Estudos e Pesquisas em Psicologia, 9(2), 512- 524. https://doi. org/10.12957/epp.2009.9120

Máximo, T. A. C. O., Araújo, A. J. S., \& Zambroni-de-Souza, P. C. (2014). Vivências de sofrimento e prazer no trabalho de gerentes de banco. Psicologia: Ciência e Profissão, 34(1), 96-111. https://dx.doi.org/10.1590/ S1414-98932014000100008.

Minayo, M. C. S. (2009). Trabalho de campo: contexto de observação, interação e descoberta. In Minayo, M. C. S. (Org.). Pesquisa social: teoria, método e criatividade (28a ed., pp. 61-77), Vozes.

Moscovici, S. (2007). Representações sociais: investigações em psicologia social. (5a ed.), Vozes.(Trabalho original publicado em 2000).

Nascimento, M. M. R. (2012). Organização do trabalho bancário de suporte e atendimento e vivências de sofrimento. [Dissertação de Mestrado, Universidade de Brasília] Repositório Institucional da UNB. http://repositorio.unb.br/handle/10482/10821.

Pina, J. A. (2012). Intensificação do trabalho e saúde dos trabalhadores na indústria automobilística: estudo de caso na Mercedes Benz do Brasil. [Tese de Doutorado, Escola Nacional de Saúde Pública Sergio Arouca] Repositório Institucional da Fiocruz. https://www.arca. fiocruz.br/handle/icict/14457.

Thompson, J. B. (2011). Ideologia e cultura moderna: teoria social crítica na era dos meios de comunição de massa. (9a ed.), Vozes. (Trabalho original publicado em 1990). 


\section{4*INTERACÃO EM ET PSICOLOGIA}

Vinuto, J. (2014). A amostragem em bola de neve na pesquisa qualitativa: um debate em aberto. Temáticas, 22(44), 203-220. https://www.ifch.unicamp.br/ojs/ index.php/tematicas/article/view/2144.

Data de submissão: 19.02 .2019 Data da primeira decisão editorial: 21.10.2019

Aceite em 05.12.2019

\section{NOTAS DE FIM}

1 - Ideologia são maneiras pelas quais o sentido (significado) serve para estabelecer e sustentar relações de poder assimétricas (relações de dominação) em situações concretas e específicas, ou seja, é o sentido conferido às ideias a serviço do poder (Thompson, 1990/2011).
Ariane Serpeloni Tavares e Rosemeire Aparecida Scopinho

2 - A vivência destas condições era constatada nos primeiros momentos da entrevista, quando os participantes eram questionados sobre a rotina de trabalho. Todos os entrevistados consideraram ter trabalhos intensificados e as condições descritas estavam de acordo com o que a literatura consultada apontava como um trabalho intensificado.

3 - Pesquisa realizada em março de 2019 , nos portais Scielo e Pepsic. Com os termos "gerente" e "gerência", no período 2014 a 2019, foi encontrada apenas uma referência que abordava as condições de trabalho dos gerentes em específico (Máximo et al., 2014). Para os termos "intensificação do trabalho", "intensificação laboral" e "trabalho intensificado" foram identificados, após leitura dos resumos, 27 artigos empíricos. Destes, 16 abordavam a intensificação laboral de docentes em instituições públicas, sete foram realizados com trabalhadores em atividades manuais, um com assistentes em administração e apenas três incluíam, entre os trabalhadores, profissionais em cargos de gestão (Cavazotte et al., 2014; Lemos et al., 2016; Máximo et al., 2014). 